\title{
Salt Dilution and Flushing Dynamics of an Impaired Agricultural- Urban Stream
}

\author{
Vasiliy Lakoba, Lauren Wind, Stephen DeVilbiss, Mary Lofton, Kristen Bretz, Alaina Weinheimer, \\ Chloe Moore, Colin Baciocco, Erin Hotchkiss, and W. Cully Hession*
}

Cite This: https://dx.doi.org/10.1021/acsestwater.0c00160

Read Online

ACCESS | Llll Metrics \& More | 回 Article Recommendations

(s) Supporting Information

ABSTRACT: Anthropogenic freshwater salinization is increasing with global change. Rising freshwater salinity threatens ecosystem biodiversity, health, and services via toxicity to organisms and mobilization of nutrients and metals. Brining roads is one major source of freshwater salinization that continues to grow with rising urbanization. While the detrimental effects of salinization in streams are well-documented, high-frequency, temporal patterns in salt transport, particularly during winter road de-icing in mixed land use landscapes, are less understood. To address this knowledge gap, we analyzed high-frequency specific conductance as a proxy for salinity across 114 high-flow events from 2013 to 2018 in an impaired stream draining mixed agriculture-urban land use. The specific conductance was highest in winter (median $=947 \mu \mathrm{S} \mathrm{cm}^{-1}$ ) and decreased with

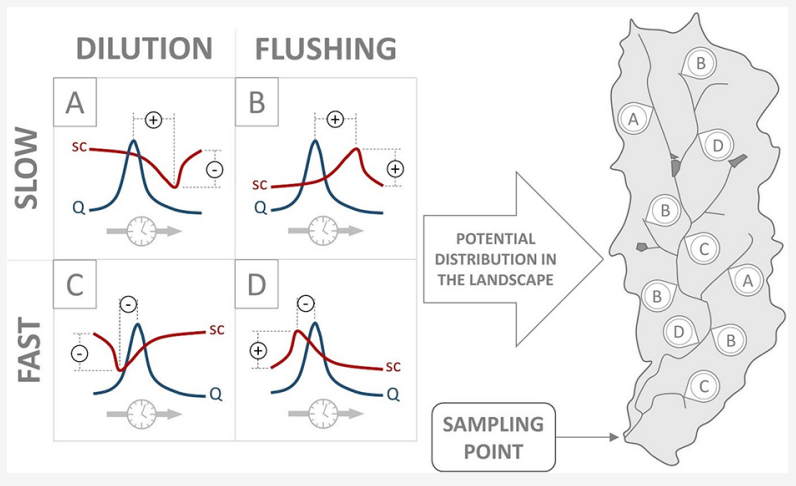
first-order kinetics up to 90 days after brining $\left(\beta_{1}=-0.003\right)$, suggesting lasting impacts of road de-icing on water quality. Although hysteresis patterns suggested a transition from distal to proximal salt sources, they showed no clear correlation of flushing versus dilution to brining events. While seasonal brining increased salinity in receiving streams, unpredictable transport dynamics reduced the efficacy of hysteresis in characterizing salt transport dynamics. Thus, the complexity of mixed land use watersheds requires more spatially and temporally explicit monitoring to characterize stream salinization dynamics.

KEYWORDS: freshwater salinization, road salts, stream ecology, land use, water contamination, urbanization

\section{INTRODUCTION}

Increasing freshwater salinity is a pervasive water quality issue worldwide and is estimated to impact $37 \%$ of the contiguous drainage area in the United States. ${ }^{1}$ Freshwater salinization is the human-facilitated increase in the concentration of total dissolved solids within freshwater ecosystems. ${ }^{2}$ The freshwater salinization syndrome was recently proposed as a way to link observed increases in conductance with associated trends in $\mathrm{pH}$ and base cations across hydrologic scales. ${ }^{1}$ Agriculture, ${ }^{3}$ resource extraction, ${ }^{4,5}$ urbanization, ${ }^{6,7}$ accelerated weathering, ${ }^{8}$ and de-icing ${ }^{9}$ all contribute to freshwater salinization. Numerous ecosystem services are negatively impacted by freshwater salinization, including the degradation of drinking water, ${ }^{10}$ reduced biodiversity caused by the toxicity of salt to freshwater organisms, ${ }^{11,12}$ and decreased water quality caused by salt-induced mobilization of contaminants, including heavy metals. ${ }^{13}$ Despite the known risks of salinized freshwater ecosystems, few water quality standards and management strategies exist. However, such strategies are sorely needed to help mitigate this issue. ${ }^{14}$

Land use within human-modified watersheds is often complex, which makes tracing different salt sources for management purposes difficult. However, the relationships between different solutes and discharge provide information about transport pathways throughout a watershed. As precipitation increases stream flow, different flow paths and sources of solutes from around the watershed are activated. ${ }^{15}$ Therefore, monitoring salt concentrations relative to changes in stream flow magnitude can help infer salt sources. For example, the relationship between discharge and conductivity ${ }^{16}$ would be positive if salt is transport-limited, because this solute enriches the stream when delivered by runoff. A negative conductivity-discharge relationship suggests that salt is a source-limited solute, because the amplified flow dilutes what little salt is present in the watershed as it moves to the stream. ${ }^{17}$ If there are multiple and/or changing sources of salt, as in a mixed land use watershed with winter brining, conductivity-discharge relationships may not be straightforward and will likely change over time and space. The

Received: September 14, 2020

Revised: October 24, 2020

Accepted: November 9, 2020 


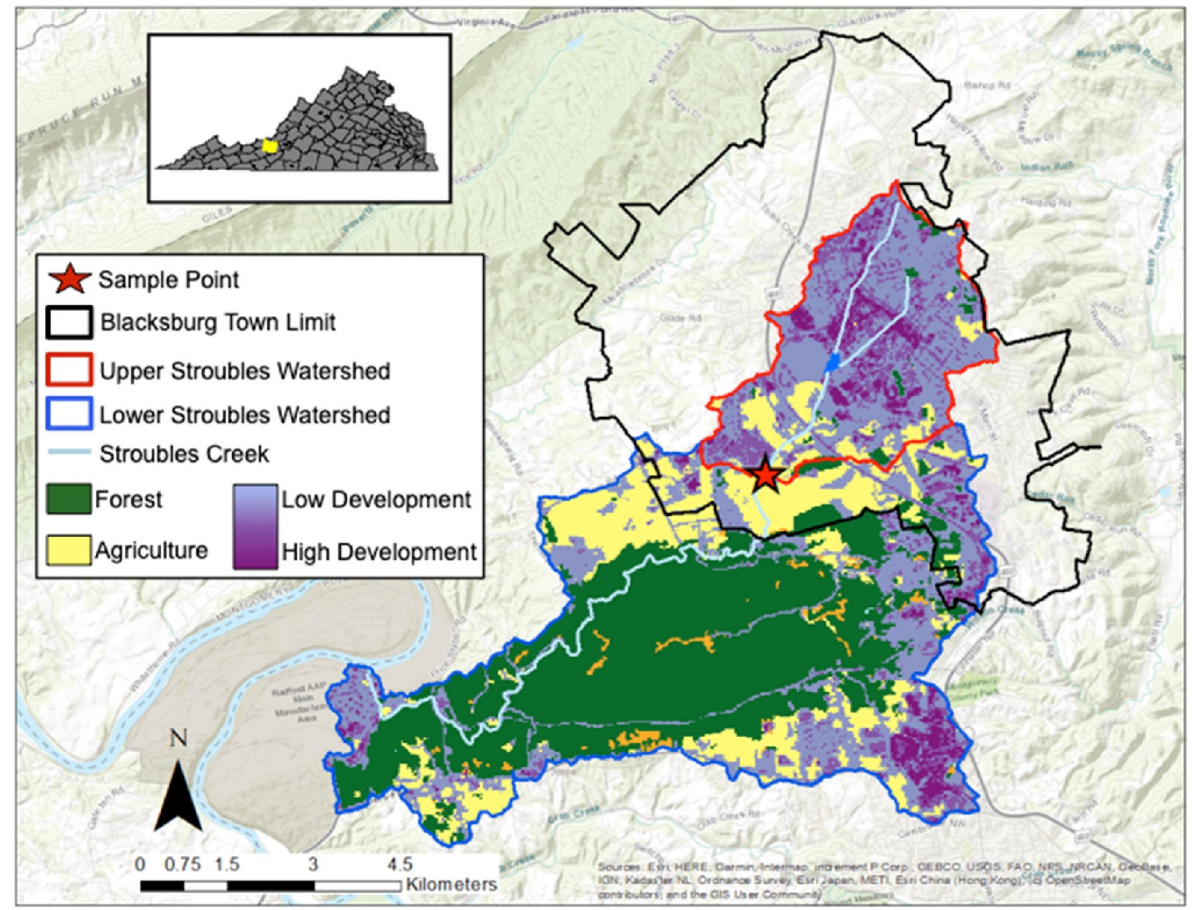

Figure 1. Stroubles Creek watershed and associated land cover, StREAM Lab (Stream Research, Education, and Management Laboratory), the monitoring and sampling point (Bridge 1), and its position in relation to the Town of Blacksburg and Montgomery County, Virginia.

consequences of changing stream flow in conjunction with salt loading from different sources in mixed land use landscapes are still not well understood.

Hysteresis, or the temporal lag between increases and decreases in discharge and the concentration of a solute, has been used to characterize the transport of numerous suspended and dissolved constituents in various watershed types. ${ }^{18,19} \mathrm{It}$ can also be used to associate two or more values of a dependent variable, such as specific conductance as a proxy for solute concentration, with an independent variable, such as discharge. $^{20}$ Indices have been developed to characterize hysteresis patterns and to infer sources and mobilization pathways of both suspended and dissolved constituents. For example, changes in salt concentrations with discharge may exhibit a clockwise loop behavior in forested watersheds, where the concentration increases quickly compared to discharge, though the directionality of the loop (clockwise versus counterclockwise) also depends on precipitation intensity. ${ }^{21,22}$ Hysteresis patterns can take shapes that are not easily categorized into common types (e.g., clockwise or counterclockwise loops), ${ }^{23}$ so indices are used to facilitate comparisons across complex, high-flow events in a watershed. However, analysis of stream solute hysteresis patterns has only recently begun to be applied to highly modified, mixed land use watersheds to study freshwater salinization. ${ }^{24,25}$

We leveraged long-term, high-frequency water quality data from a stream draining a mixed agricultural-urban watershed to ask how transport dynamics through a modified, heterogeneous watershed change as a result of high-flow event flushing and dilution to reflect sources of salt. We identified temporal patterns in specific conductivity and characterized hysteresis patterns to infer salt sources and mobilization patterns. We hypothesized that high-flow events following winter brining would have different hysteresis loop behaviors (e.g., direction, thickness, and shape) compared to those of events that occurred later in time after a brine application. We expected hysteresis loops to be clockwise during flow events following brining, indicating a first flush of a proximal salt source. Salt loading transport dynamics can better inform salinization mitigation efforts, especially in heterogeneous human-modified watersheds.

\section{EXPERIMENTAL METHODS}

Study Site. Stroubles Creek is an approximately $19 \mathrm{~km}$ long tributary of the New River that begins in the town of Blacksburg, VA, and flows through the Virginia Tech campus (Figure 1). The region experiences an average of $104 \mathrm{~cm}$ of precipitation and $68.5 \mathrm{~cm}$ of snowfall annually. Stroubles Creek is a highly modified stream that drains a mixed land use watershed with an area of approximately $14.45 \mathrm{~km}^{2}$ at our monitoring location. The Stroubles Creek watershed is $>80 \%$ developed. $^{26}$ In 1998, an $8 \mathrm{~km}$ portion of Stroubles Creek flowing through the upper watershed was listed on the U.S. Environmental Protection Agency's (EPA) 303d list of impaired waters. A subsequent total maximum daily load (TMDL) analysis identified sediment as the primary stressor, and a benthic TMDL was approved by the EPA in 2004 noting benthic impairment in the associated waterways. ${ }^{27}$ The Stroubles Creek TMDL implementation plan was subsequently developed, ${ }^{28}$ and various best management practices have been implemented to reduce sediment loads, including stream restoration, riparian plantings, and urban stormwater management practices. ${ }^{29}$ In 2010, Wynn et al. ${ }^{30}$ conducted a threestage restoration effort on $2.1 \mathrm{~km}$ of the impaired reach and a small tributary that are now encompassed by the Virginia Tech Stream Research, Education, and Management (StREAM) Lab (vtstreamlab.weebly.com/). While the restoration and implementation of various best management practices have led to some improvement in the benthic community monitored by 
A

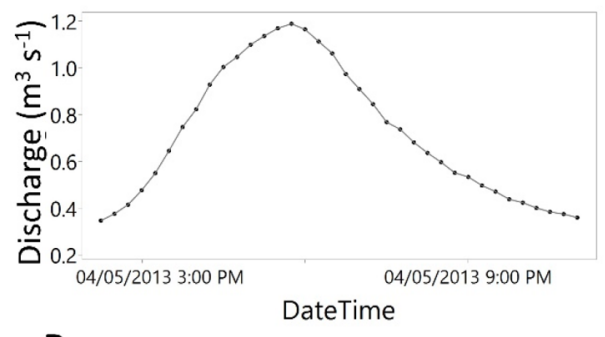

B

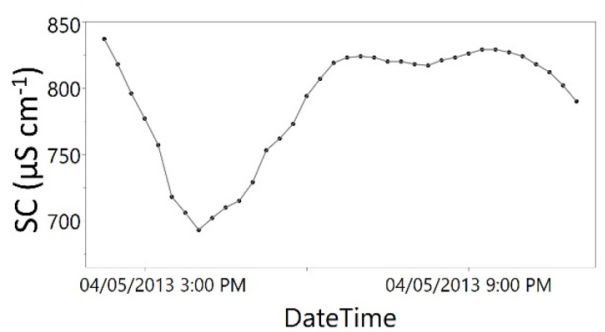

C

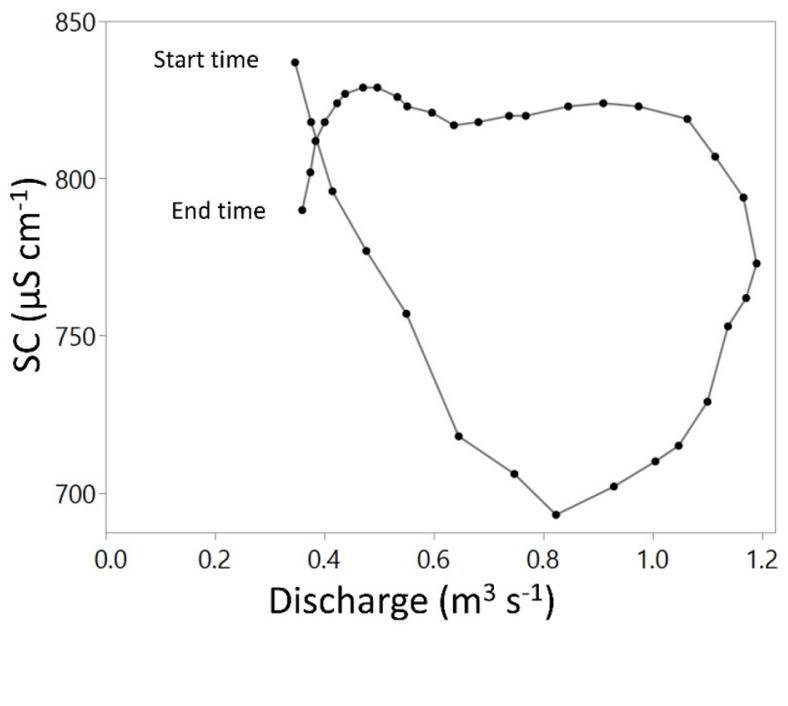

Figure 2. Hydrographs of (A) discharge and (B) conductivity. (C) Discharge-conductivity hysteresis plot for one of the high-flow events used in this study's analyses. The hydrographs of other events in the 2013-2018 dataset vary widely in amplitude and duration, as well as in the general shape of their respective hysteresis plots.

the Virginia Department of Environmental Quality downstream, Stroubles Creek is still listed as impaired.

Stroubles Creek has been extensively studied since the early 1900s, with much of the work focusing on bacterial ecology and water quality. ${ }^{31,32}$ Over the past few decades, research projects have diversified to include a variety of overlapping fields, including hydrology, ${ }^{33,34}$ land use and imaging, ${ }^{35,36}$ restoration and monitoring, ${ }^{37,38}$ ecosystem metabolism and biogeochemistry, ${ }^{39,40}$ and organismal studies both within the stream and along the riparian corridor. ${ }^{41,42}$ Pressures from the urbanizing watershed, Virginia Tech's expansion, and climate change have continued to increase anthropogenic stress on this water body. One specific pressure is the use of road salts by both the Town of Blacksburg and the Virginia Tech Department of Facilities Operations, as well as the latter's use of de-icing brine obtained from its Central Steam Plant. The exact compositions of the road salts and brine are unknown to the authors. The well-characterized nature of this stream, the landscape heterogeneity of its watershed, and the availability of high-frequency, long-term water quality data make Stroubles Creek an ideal system for assessing historical trends and event-based loading and transport dynamics of salts.

Long-Term Conductivity Data. In December 2012, an in situ YSI 6920 V2 instrument (Yellow Springs Instruments, Yellow Springs, OH) was placed in a $2.7 \mathrm{~m}$ wide channel (Sample Point, Figure 1) with an annual average discharge $(Q)$ of $0.2 \mathrm{~m}^{3} / \mathrm{s}$ within the StREAM Lab to continuously record water quality parameters every $15 \mathrm{~min}$. Water quality parameters collected include dissolved oxygen (milligrams per liter, percent), $\mathrm{pH}$, specific conductance (SC; microsiemens per centimeter), turbidity [nephelometric turbidity units (NTU)], and water temperature (degrees Celsius), of which only SC was analyzed in our study. Additionally, a Campbell Scientific CS451 pressure transducer was installed to continuously record the stream stage height $(\mathrm{m})$ every 10 min (Campbell Scientific, Logan, UT). The long-term Stroubles Creek water quality dataset, associated quality assurance methods, and stage-discharge relationship can be accessed via the Environmental Data Initiative data portal. ${ }^{43}$

For this study, continuous SC and associated stage datasets from 2012 to 2018 were passed through a rigorous quality control process before further analysis in $\mathrm{R}$ version 3.6.1. ${ }^{44} \mathrm{SC}$ and stage data were flagged as "suspect" when known sonde limitations and sensor error codes occurred $(<0.005 \%$ of the total dataset). SC records were also flagged due to the conductivity sensor on the YSI instrument being above the stream water level during base flow conditions (93\% of the total dataset). As this study solely focuses on the 90th percentile of flow events, with an average flow rate of $1.55 \mathrm{~m}^{3}$ $\mathrm{s}^{-1}$, the exclusion of potentially suspect water quality data during low-flow periods did not affect our analyses or subsequent results.

Flow Event Manual Inspection and High-Flow Event Identification Criteria. We selected the 90th percentile of all flow events, ranked by net $Q$ which resulted in a subset of 377 flow events. We visualized and checked each of these events against the corresponding SC records to identify eligible data for analysis (Figure S1). Flow event visualization was conducted by at least two investigators who systematically included or excluded potential high-flow events on the basis of three criteria (Text S1). The criteria for a legitimate high-flow event included (1) analyzing the rising limb of each flow event to ensure inclusion of a frequently occurring initial $Q$ peak representing direct discharge from a large urban development area immediately upstream from the YSI instrument location point (Figure S2), (2) analyzing the falling limb of the flow event to make sure that $Q$ returned to base flow, and (3) identifying where multiple successive events satisfied criteria 1 and 2 , in which case we split them into discrete events. If there was irreconcilable disagreement between the two investigators on classification, the event was excluded $(n=93)$. After meeting all inclusion criteria, 185 high-flow events within the 90th percentile of $Q$ (49\% inclusion) were identified for further analysis. 
High-Flow Event and Associated Brine Event Parameters. For the 185 high-flow events analyzed, we extracted date, duration, season, $S C$ ranges, and $Q$ ranges (Table $S 1$ ). In addition, using known road brining dates obtained from the Facilities Department at Virginia Tech, we calculated the number of days since brining (DSB) for all events. Over the seven-year dataset, there were 19 known brine applications (Table S2). Due to missing salt brining records for the winters of 2012 to 2013 and 2015 to 2016, flow events from these periods until the following winters (2014 to 2015 and 2016 to 2017, respectively) were excluded, leaving 114 events for our final high-flow dataset (Figure S1).

Hysteresis and Flushing Index Calculations. We used the overall shape of associated hysteresis loops to further characterize relationships between $S C$ and $Q$ during flow events. ${ }^{45}$ The hysteresis index (HI) describes the direction of the hysteresis loop and can be used to infer whether constituent sources are proximal, or readily transported, versus distal, or slower to mobilize ${ }^{16}$ (Figure 2). A clockwise loop (positive HI), where the concentration increases quickly compared to discharge (also called "first flush"), suggests a proximal source, while a counterclockwise loop (negative HI), where concentrations increase slowly compared to discharge, suggests a distal source. The magnitude of the $\mathrm{HI}$ reflects the thickness of the loop shape; a larger absolute magnitude means that there is a greater difference between the rising and falling limbs of the flow event, yielding a wider, more circular looking loop. ${ }^{42}$ The absolute magnitude of HI may reflect antecedent flow conditions or variations in $Q$ through the event. ${ }^{43}$ Three main shapes of hysteresis loops (circular, figure eight, and linear) are commonly observed in nature and provide insight into the behavior of the dependent variable during high-flow events. ${ }^{44,45}$ A circular loop in either direction suggests that the times of peak concentration and peak discharge are offset, while a figure-eight loop indicates that there are multiple peaks of both variables during the event and their timings relative to each other change throughout the event. ${ }^{44}$

Hysteresis and flushing indices (HI and FI, respectively) were calculated using normalized SC and normalized $Q$ values over the duration of each event. The HI for each event was calculated following methods from Zuecco and colleagues. ${ }^{45}$ First, $Q$ and SC were normalized as

$$
\begin{aligned}
& u(t)=\frac{x(t)-x_{\min }}{x_{\max }-x_{\min }} \\
& v(t)=\frac{y(t)-y_{\min }}{y_{\max }-y_{\min }}
\end{aligned}
$$

where $x(t)$ and $y(t)$ represent $Q$ (cubic meters per second) and SC (microsiemens per second) at time $t$, respectively. $x_{\max }$ $x_{\min }, y_{\max }$ and $y_{\min }$ represent the maximum and minimum $Q$ and SC, respectively, during the flow event. $u(t)$ and $v(t)$ are the normalized values of $x(t)$ and $y(t)$, respectively. The HI was calculated as

$$
\mathrm{HI}=\sum_{k=1}^{n} \Delta A_{[i, j]}
$$

where $n$ is the number of intervals and $\Delta A$ is the difference between definite integrals on the rising and falling curves of the hysteresis loop for the upper and lower limit of the SC interval $[i, j]$ and is calculated as

$$
\Delta A_{[i, j]}=A_{\mathrm{r}[i, j]}-A_{\mathrm{f}[i, j]}
$$

where $A_{\mathrm{r}[i, j]}$ and $A_{\mathrm{f}[i, j]}$ are the definite integrals for the rising and falling limbs, respectively.

The FI for each flow event was calculated by subtracting the normalized SC at the start of the event $[v(t=0)]$ from the normalized SC at peak $Q$ during the same event $\left[v\left(t=x_{\max }\right)\right)$. We generated hysteresis loops for each flow event using a $\mathrm{HI}$ and FI computational tool ${ }^{45}$ and calculated the minimum and maximum differences between the rising and falling limbs of each event to describe hysteresis loop direction, shape, and class. $^{45}$ Of the 114 events analyzed, 26 failed to generate a hysteresis loop and affiliated indices because $Q$ did not return to its starting value of the event's rising limb. These failures to return to baseline $Q$ were typically related to flow events in quick succession and were independent of incongruities not covered by the baseline SC criterion, criterion 2 .

Effects of Testing Days Since Brine on Individual High-Flow Events. Using the 114 events identified with known DSB values (Figure S1), we used one-way analysis of variance (ANOVA) to examine differences in event $\mathrm{SC}_{\max }$ among months, followed by a Tukey HSD test to identify contrasting subsets of months. A breakpoint was used to constrain regressions to a duration post-brining where brine was still impacting stream salt concentrations. We used linear regressions to test the effect of days since brining (DSB) on $\mathrm{HI}$, IHIl, and FI. This analysis was limited to flow events within the first 90 DSB based on a breakpoint identified via a segmented linear model, ${ }^{46}$ which indicated that SC decreased only up to $90 \mathrm{DSB}$. Using this breakpoint to subset our data, we conducted linear regression of $\log _{10}\left(\mathrm{SC}_{\max }\right)$ on DSB to calculate a decay rate of SC.

Statistical Analysis. Regression and Tukey HSD analyses were performed using JMP, version 15 (SAS Institute Inc., Cary, NC), and R version 3.6.1. ${ }^{44}$ The breakpoint analysis was performed as described by Muggeo. ${ }^{46}$ The land use map in Figure 1 was produced using ArcGIS version 10.7 (Environmental Systems Research Institute, Inc., Redlands, CA).

\section{RESULTS}

Flow Event Magnitude, SC, and Indices Follow Mixed Seasonal Patterns. Flow events had the highest $Q$ values in summer and fall and the lowest $Q$ values in winter, while changes in event duration did not fit a seasonal pattern. Across the 185 analyzed events from 2013 to 2018, the longest events $[$ mean \pm standard error $(\mathrm{SE})]$ were in February $(14.1 \pm 4.6$ h), July $(14 \pm 3.3 \mathrm{~h})$, and March $(12.7 \pm 2.6 \mathrm{~h})$. The shortest events (by $\sim 2$-fold) were in September $(5 \pm 0.98 \mathrm{~h})$, August $(6.7 \pm 0.59 \mathrm{~h})$, and June $(7.1 \pm 0.78 \mathrm{~h}) . Q_{\max }$ had a trend dissimilar to that of duration, with the highest flow in October $(6.2 \pm 1.2 \mathrm{cms})$, June $(5.3 \pm 0.98 \mathrm{cms})$, and July $(4 \pm 0.94$ cms). The lowest- $Q_{\max }$ events (by $\sim 2$-fold) occured in March $(1.9 \pm 0.41 \mathrm{cms})$, February $(2.1 \pm 0.88 \mathrm{cms})$, and December $(2.4 \pm 0.67 \mathrm{cms})$.

There were pronounced differences in $\mathrm{SC}_{\max }$ during flow events occurring across different months and seasons, but no seasonal patterns emerged for $\mathrm{HI}$, |HIl, or FI. The highest median $\mathrm{SC}_{\max }$ values were in February $\left(947 \mu \mathrm{S} \mathrm{cm}{ }^{-1}\right)$, March $\left(845 \mu \mathrm{S} \mathrm{cm} \mathrm{cm}^{-1}\right)$, and January $\left(713 \mu \mathrm{S} \mathrm{cm} \mathrm{cm}^{-1}\right)$. The lowest median $\mathrm{SC}_{\max }$ values (by $\sim 2$-fold) were in August (435 $\mu \mathrm{S}$ $\left.\mathrm{cm}^{-1}\right)$, July $\left(517 \mu \mathrm{S} \mathrm{cm}^{-1}\right)$, and June $\left(522 \mu \mathrm{S} \mathrm{cm}^{-1}\right)$. There was no apparent seasonal pattern in $\mathrm{HI}$, which was normally distributed $(-0.05 \pm 0.024)$. February $(0.14 \pm 0.09)$, June 
A

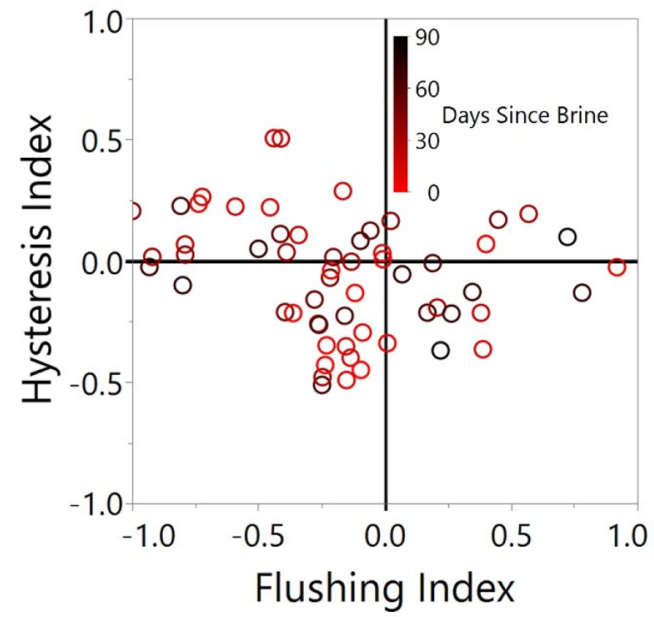

B

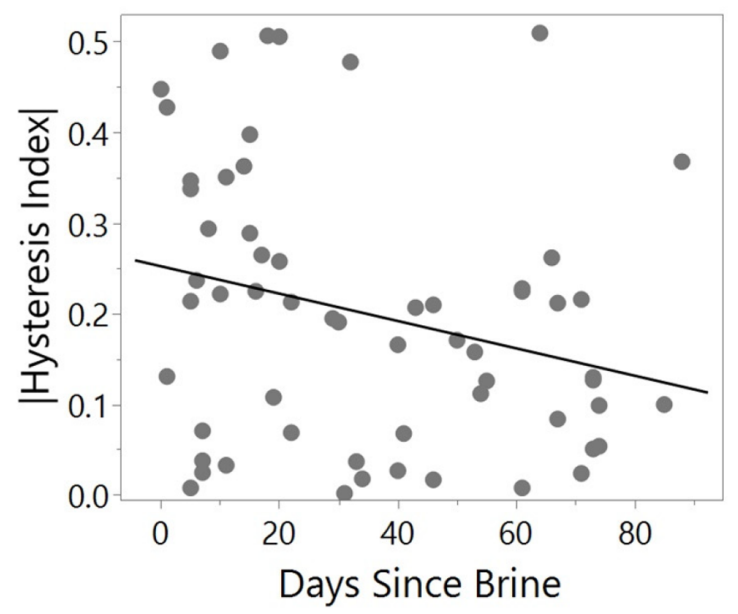

Figure 3. (A) Hysteresis and flushing indices of 57 high-flow events between 2013 and 2018. The marker color indicates days elapsed from the most recent road salt brine application event. (B) Negative relationship between days since brining and IHII. Flow events in both panels are limited to those that are positively known to be $<90$ DSB and did not fail to generate a hysteresis loop $(n=57)$.

$(0.01 \pm 0.06)$, and November $(0.09 \pm 0.09)$ were the only months when $\mathrm{HI}$ averages were positive, implying proximal salt sources. Meanwhile, the lowest-HI months were August $(-0.22 \pm 0.07)$, December $(-0.16 \pm 0.07)$, and January $(-0.16 \pm 0.09)$. Similarly, FI and $|\mathrm{HI}|$ were not related to season. Furthermore, FI was not related to DSB. Forty-two high-flow events had negative FI values, while only 14 events had positive FI values. Multiple logistic regression on event duration, $\mathrm{SC}_{\max }, Q_{\max }$ and month found flow event duration to be a significant predictor of whether FI was positive or negative. The durations of flow events with positive FI values were significantly shorter than the durations of those with negative FI values, lasting 8.9 and $13.0 \mathrm{~h}$, respectively ( $p=$ 0.038 ). There was no strong ordination of events in $\mathrm{HI}-\mathrm{FI}$ space based on DSB beyond the apparent effect on $|\mathrm{HI}|$ (Figure 3B).

Flow Event $\mathrm{SC}_{\max }$ Decreases with DSB. $\mathrm{SC}_{\max }$ was highest and most variable in winter months. Given winter storm timing and resulting road brining, DSB was lowest in February (18.6 \pm 3.8 days) and peaked in October (209.2 \pm 9.3 days). Individual flow events with exceptionally high $\mathrm{SC}_{\max }$ values occurred in March $\left(3921 \mu \mathrm{S} \mathrm{cm}^{-1}\right)$ and February (2912 $\left.\mu \mathrm{S} \mathrm{cm}^{-1}\right)$. Among the 114 high-flow events associated with known brining dates, the median SC range over an event's duration was $287 \mu \mathrm{S} \mathrm{cm} \mathrm{cm}^{-1}$ and the minimum and maximum were 28 and $3453 \mu \mathrm{S} \mathrm{cm} \mathrm{cm}^{-1}$, respectively. Months with the highest variance in event $\mathrm{SC}_{\max }$ were February $(\mathrm{SE}=239 \mu \mathrm{S}$ $\mathrm{cm}^{-1}$ ) and November $\left(\mathrm{SE}=227 \mu \mathrm{S} \mathrm{cm}^{-1}\right)$.

Months with higher SC values during high-flow events were also associated with greater average temporal proximity to salt brine applications (Figure 4) and also had the lowest mean DSB (17.8 days in February and 30.8 days in March). The months with the lowest $\mathrm{SC}_{\text {med }}$ values during flow events were associated with higher mean DSB (157.4 days in August, 142.6 days in July, and 204 days in October). While August, July, and October were associated both with the highest DSB and the lowest SC, it is most likely that DSB does not explain SC during these months, when winter brining is mechanistically irrelevant. ${ }^{47} \mathrm{SC}_{\max }$ was higher during flow events that occurred closer in time to salt brine application (i.e., lower DSB). This

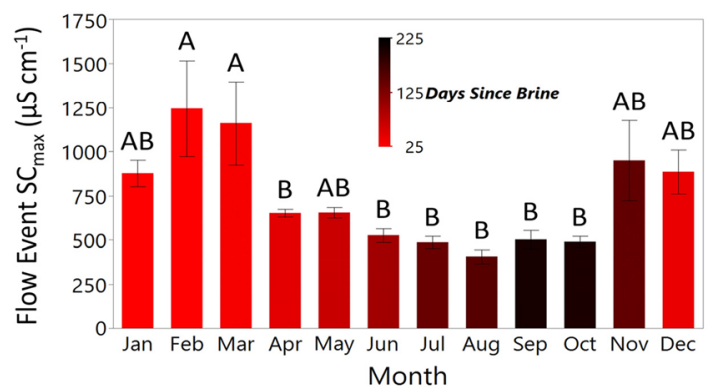

Figure 4. Monthly mean \pm SE of maximum specific conductance during 114 high-flow events pooled across 2013-2018. The bar color represents the monthly mean time since the last brine event. Significant differences among months were derived via a post hoc Tukey HSD $(p<0.0001)$ and are indicated by the letters on each bar, such that months with no letters in common are significantly different from one another (i.e., $A$ vs $B$, but not $A B$ vs $A$ or $A B$ vs $B$ ).

pattern was present both on an individual event basis as and when aggregated by month (pooled across 2013-2018, excluding 2016 due to a lack of brining records). $\mathrm{SC}_{\max }$ of $50 \%(n=90)$ of all high-flow events occurred within the first $20 \%$ of their duration, suggesting mobilization of salts in the "first flush" of the event.

$\mathrm{SC}_{\max }$ declined with time since brining. Segmented regression analysis of disaggregated $\mathrm{SC}_{\max }$ against DSB (Figure $5 \mathrm{~A})$ resulted in a breakpoint of $90.8 \pm 16.1$ days $(p<0.0001)$. For flow events within 90 days of the last brine event, regression of $\log \left(\mathrm{SC}_{\max }\right)$ on DSB (Figure $5 \mathrm{~B}$ ) yielded a decay rate of -0.003 day $^{-1}(p<0.0001)$.

The Absolute Value of HI Decreases with Time Since Brining Event. There was no significant change in $\mathrm{HI}$ within 90 DSB. However, IHI decreased with DSB $[p=0.041$ (Figure 3B)], falling by an average of 0.05 every 30 days. A greater $|\mathrm{HI}|$ indicates a greater hysteresis loop size and, therefore, a longer temporal lag between $\mathrm{Q}_{\max }$ and $\mathrm{SC}_{\max }$ among events most immediately following brining. Across the $<90$ DSB high-flow events, $|\mathrm{HI}|$ ranged from 0.008 to 0.51 , indicating that $Q_{\max }$ lagged $\mathrm{SC}_{\max }$ by $2.5-2.75 \mathrm{~h}$. 

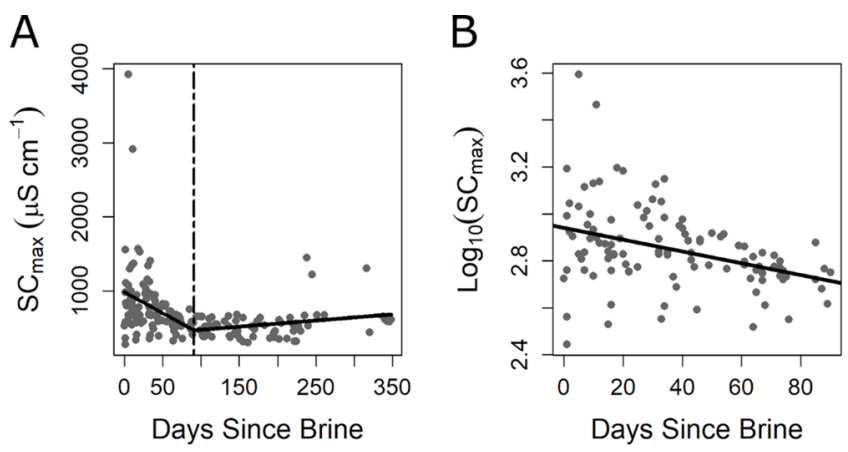

Figure 5. (A) Breakpoint analysis highlighting two distinct relationships between specific conductance and days since brine. The dotted line is where the model indicated that conductivity stopped decreasing with days since brine. Breakpoint $=90.8 \pm 16.1$ days $(p$ $<0.0001 ; r^{2}=0.1705$ ). (B) Flow event maximum conductivity regressed on days since brine yields a significant decay rate $\left(\beta_{1}=\right.$ $\left.-0.003 ; p<0.0001 ; r^{2}=0.129\right)$. Flow events in panel B are limited to those within $90 \mathrm{DSB}$.

\section{DISCUSSION}

Despite increasing interest in salinization as an environmental stressor and water quality issue, high-frequency characterizations of the relationship between flow and salt dynamics in modified watersheds are few. To that end, we conducted a hysteresis analysis of 114 high-flow events in a developing, mixed land use watershed to identify temporal patterns in salt concentrations and infer salt sources and mobilization patterns. Due to the high degree of urbanization and agriculture in the watershed, Stroubles Creek has high background SC, even in the absence of brine. SC was higher in January through March, when brining salts are frequently applied to improve road safety during winter storms. Flow event SC in these months $\left(1079 \pm 116 \mu \mathrm{S} \mathrm{cm}^{-1}\right)$ peaked at values nearly double that in April through December $\left(625 \pm 28 \mu \mathrm{S} \mathrm{cm}^{-1}\right)$. Post-brining flow events had greater temporal lags between peaks in $Q$ and SC, suggesting that post-brining high-flow events were connected with more distal salt sources compared to highflow events at other times of year.

Brining Modulates the Seasonality of SC. $\mathrm{SC}_{\max }$ during flow events was highest in the winter months of February and March, suggesting that, even though most high-flow events displayed a diluting behavior (i.e., negative FI), brine application increases background salt concentrations in the stream. Winter months also had the greatest variability in $\mathrm{SC}_{\max }$. This could be explained by the episodic nature of brine application due to forecast uncertainty because precipitation does not always occur after brining. Thus, salts can accumulate on roads during successive brining events, resulting in larger pulses once they are flushed into surface waters. This can be exacerbated in urbanized watersheds with greater impervious surface area, compared to rural or undeveloped counterparts. ${ }^{48}$ Other urbanized streams have shown similar seasonal trends. For example, SC and $\mathrm{Cl}^{-}$concentrations were higher in winter months in urbanized streams draining St. Louis, MO, a pattern attributed to road salt application. ${ }^{49}$ The highest variability of both SC and $\mathrm{Cl}^{-}$concentrations occurred during winter, ${ }^{49}$ which was attributed to flashier (i.e., rapid, short-term changes in streamflow) hydrographs often observed in urban streams. ${ }^{50}$ While elevated conductivity during winter has been found to be common in watersheds with even small amounts of impervious surface, agricultural watersheds have been found to have significant year-round salinity issues due to fertilizer

The Complex Landscape Matrix of Salt FLUSHING and DILUTION

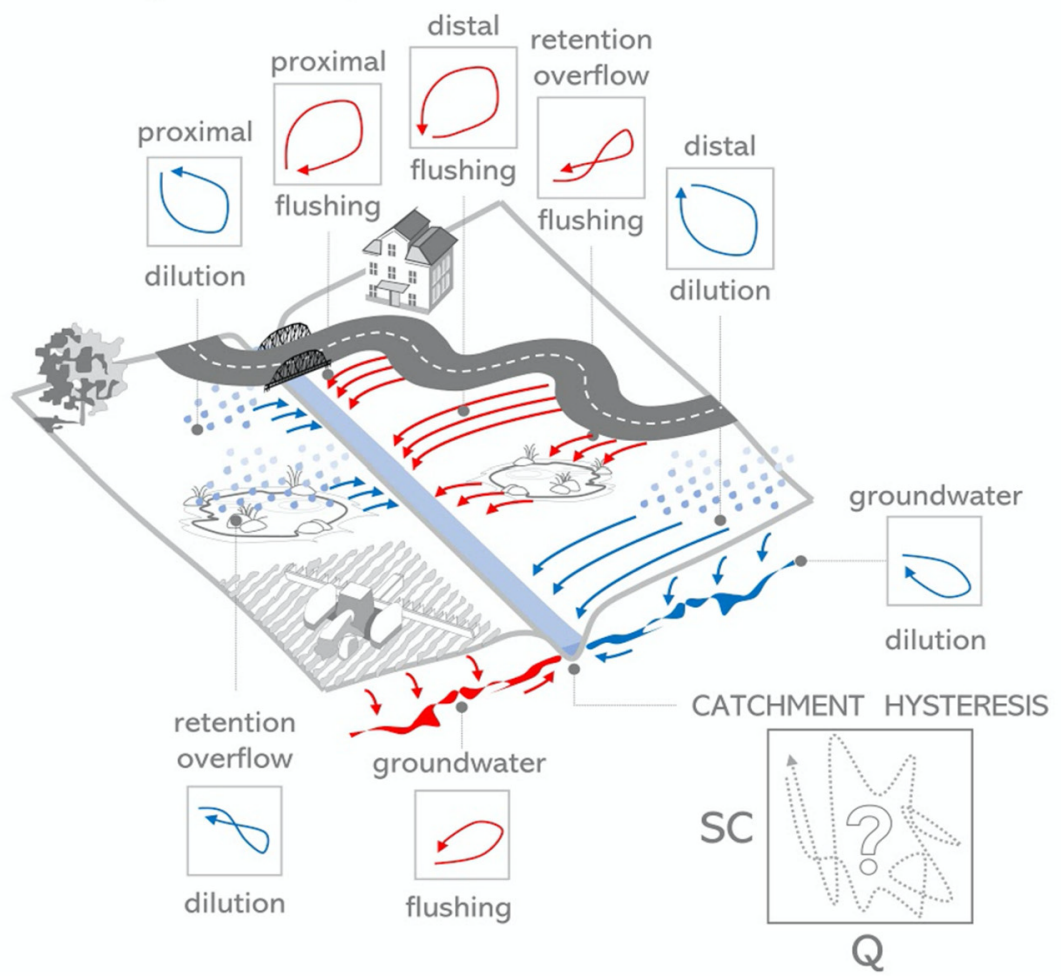

Figure 6. Conceptual figure representing the complexity of flushing and dilution hysteresis patterns in a mixed land use watershed, along with their hypothesized drivers. The simultaneous contributions of these drivers yield a complicated cumulative hysteresis pattern at the sample point. 
application. ${ }^{51}$ In Appalachian streams, urban sites often have increased $\mathrm{SC}$ and $\mathrm{Cl}^{-}$concentrations relative to those of forested streams, with elevated $\mathrm{Cl}^{-}$concentrations coming from diverse sources, including municipal sewage releases at some sites, which do not occur in Stroubles Creek. ${ }^{52}$ While SC patterns were predictable at seasonal time scales, event-based dynamics were highly variable.

Hysteresis Patterns Are Complex in Modified Stream Networks. Hysteresis patterns of SC varied significantly, showing few relationships with brining. While there was a clear negative relationship between $\mathrm{SC}_{\max }$ and DSB (Figure 5), hysteresis patterns did not respond to DSB consistently. Although there were no relationships between FI or HI and $\mathrm{DSB},|\mathrm{HI}|$ decreased with DSB, indicating that in the absence of brining, the relationship between $\mathrm{SC}$ and $Q$ becomes more linear. As the proximity to brining activities increases, that relationship becomes less linear, although there was no consistency in loop direction (clockwise vs counterclockwise). The lack of consistency in loop direction could be explained by watershed complexity (Figure 6). For example, there are several small impoundments in Stroubles Creek upstream of our monitoring site. Depending on intensity and retention time, overflow from retention ponds can vary significantly, which could influence whether salty runoff is retained and slowly released (low intensity) or flushed rapidly through the system (high intensity). As a result of runoff retention, SC may not exhibit first-flush dynamics. ${ }^{53}$ We expect this was the case in our analysis, further complicating interpretation of hysteresis patterns.

In addition to numerous impoundments and stormwater best management practices (BMPs), the Stroubles Creek watershed also has isolated impervious regions (e.g., large parking lots) that directly drain into the creek above the sample site (Figure S2). Because these regions are isolated from the rest of the watershed, they exert their own unique effects on stream discharge and chemistry. ${ }^{54}$ During many events, the hysteresis patterns from these isolated impervious regions were distinct (Figure S2), and in some cases, opposite of water draining the rest of the watershed. The combined effects of three impoundments in the watershed and numerous urban stormwater BMPs could explain the lack of trends between proximity to brining and hysteresis metrics (Figure 6). Depending on hydrologic factors (e.g., rain vs snow, storm intensity, and duration), the relative influence of these features may shift, changing the aggregate hysteresis patterns observed at the sensor. Furthermore, while additional de-icing takes place throughout developed parts of the watershed (e.g., different amounts of solid salt application on sidewalks and parking lots vs liquid brining applications), data on salt application by businesses and homeowners are not available to support further analyses of variable patterns in conductivity. Agricultural inputs, ${ }^{51}$ deteriorating infrastructure, ${ }^{52}$ and walkway de-icing ${ }^{53}$ add additional layers of complexity to urbanized watershed salt dynamics. The SC hysteresis patterns in unmodified streams are generally less complex and can be sufficiently characterized by single-point monitoring. ${ }^{54}$ However, for modified streams, we suggest that strategic spatial monitoring of water quality that captures the effects of unique watershed features (e.g., impoundments, urban stormwater infrastructure, and direct impervious drainage areas) is needed to fully capture and understand salt transport pathways and dynamics in developed landscapes. ${ }^{55}$
Although there were no linear relationships between FI and DSB within 90 days, most flow events had negative FI values (Figure 3A). While negative FI values usually suggest source limitation, the likely cause of the predominance of negative FI values in the Stroubles Creek watershed is that salts are transport-limited during most flow events within 90 DSB (Figure 3A). Because brining primarily occurs in the upper watershed, negative FI hysteresis patterns likely are the result of transport time from impervious surfaces to the sensor downstream in the watershed, as opposed to source limitations. ${ }^{56}$ Although FI was negative, SC began to increase on the falling limb of the event, which could be explained by salt reaching the monitoring site after $Q_{\max }$. However, in the absence of salt application in summer months, salts could originate from numerous additional sources, including withinchannel sources (e.g., groundwater and bank erosion), illicit discharges, fertilizer application, or concrete dissolution. ${ }^{56}$ In the summer, it is likely that runoff dilutes salt concentrations, as the rising and falling limbs display similar behavior. Thus, salt sources at different times of the year can have significant impacts on salt dynamics in streams that can affect multiple aspects of stream ecosystem health. Evans and Davies ${ }^{57}$ posited that hysteresis analysis can make it possible to predict relative solute values based on simple criteria. However, our results suggest that as watersheds become more modified, simple hysteresis relationships may not suffice.

Brine Application Has Lasting Effects on Water Quality. Brining can impact salt dynamics in streams for months after application. $\mathrm{SC}_{\max }$ was highest after brining activities but decreased exponentially with time up to 90 DSB (Figure 5). Although it does not take 90 days to transport brine from impervious surfaces to adjacent streams, impoundments and stormwater infrastructure will increase salt residence time in watersheds. Our analyses suggest that, by retaining storm flows, impoundments may slowly release saltier water for months, even after brining has ceased. In urbanized watersheds, stormwater ponds have in some cases been shown to facilitate delayed salt plume movement to surface waters and, thus, fail to protect groundwater as intended. ${ }^{58}$ Additionally, in karst landscapes such as the Stroubles Creek watershed, salty meltwater is rapidly transported through preferential flow paths during winter and spring storms while remaining salt is slowly transported through rock over months or years. ${ }^{59}$ Road salts can also be retained in soils and released episodically by

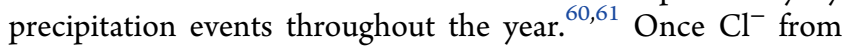
road salt infiltrates soil, it continually contributes to increased conductivity during non-brining periods because of its slow movement through the unsaturated zone and into groundwater. $^{62}$

\section{CONCLUSIONS}

High-frequency water quality monitoring has vastly improved our understanding of the impacts of land use on aquatic ecosystems. However, more nuanced monitoring plans must be developed to capture the complexity within modified watersheds, especially given predicted future increases in stream and river conductivity. ${ }^{63}$ In mixed land use watersheds such as Stroubles Creek, watershed features (e.g., impoundments, stream burial, and channelization) can result in multivalent relationships between discharge and salinity. While single-point monitoring will capture the aggregate effects of salt on complex landscapes, it cannot discern the distinct effects of individual features and actions, including BMPs and salt applications, on 
stream solute dynamics. Further research on salt transport is needed to quantify patterns in spatial and temporal variability that can adequately inform strategies for freshwater salinity management. This will help to parse and compare salinization contributions of specific land use classes, as Vaughan and colleagues $^{20}$ investigated dissolved organic carbon and nitrates in watersheds dominated by agriculture, urbanization, and forest cover. Thus, increasing the spatial resolution of water quality sensors will greatly improve our ability to understand salt dynamics in complex streams. This, in turn, will serve managers in their efforts to minimize the impacts of upland salt use on water quality.

\section{ASSOCIATED CONTENT}

\section{(s) Supporting Information}

The Supporting Information is available free of charge at https://pubs.acs.org/doi/10.1021/acsestwater.0c00160.

Description of high-flow event identification and processing (Text S1), metadata of the 185 identified high-flow events (Table S1), salt brine events (Table S2), high-flow event identification flowchart (Figure S1), and urban site identification and example of the first peak of a high-flow event (Figure S2) (PDF)

\section{AUTHOR INFORMATION}

\section{Corresponding Author}

W. Cully Hession - Biological Systems Engineering, Virginia Tech, Blacksburg, Virginia 24060, United States;

Email: chession@vt.edu

\section{Authors}

Vasiliy Lakoba - School of Plant and Environmental Sciences, Virginia Tech, Blacksburg, Virginia 24060, United States

Lauren Wind - Biological Systems Engineering, Virginia Tech, Blacksburg, Virginia 24060, United States; 이이.org/ 0000-0002-0805-1086

Stephen DeVilbiss - School of Plant and Environmental Sciences, Virginia Tech, Blacksburg, Virginia 24060, United States

Mary Lofton - Department of Biological Sciences, Virginia Tech, Blacksburg, Virginia 24060, United States

Kristen Bretz - Department of Biological Sciences, Virginia Tech, Blacksburg, Virginia 24060, United States

Alaina Weinheimer - Department of Biological Sciences, Virginia Tech, Blacksburg, Virginia 24060, United States

Chloe Moore - Department of Biological Sciences, Virginia Tech, Blacksburg, Virginia 24060, United States

Colin Baciocco - Yale College, Yale University, New Haven, Connecticut 06520, United States

Erin Hotchkiss - Department of Biological Sciences, Virginia Tech, Blacksburg, Virginia 24060, United States

Complete contact information is available at: https://pubs.acs.org/10.1021/acsestwater.0c00160

\section{Author Contributions}

L.W. and S.D. contributed equally to this work.

\section{Notes}

The authors declare no competing financial interest.

\section{ACKNOWLEDGMENTS}

The authors acknowledge and thank The Global Change Center at Virginia Tech for supporting the Interfaces of Global
Change fellows' collaboration on this project. The Virginia Tech Water Confluence REEU Summer 2019 cohort was instrumental in continuing this project's efforts, specifically mentors Brian Badgley and Merideth Steele of Virginia Tech's School of Plant and Environmental Sciences and students Kestrel Owens and Isabelle Largen. The authors are thankful that USDA-NIFA Grant VA-2017-06438 supported the undergraduate researchers. Additionally, Laura Lehmann, the StREAM Lab Manager, was instrumental in maintaining and supplying the long-term water quality dataset that we used. The authors thank Charlie Aqualina for his help with visualizing land cover within the watershed.

\section{REFERENCES}

(1) Kaushal, S. S.; Likens, G. E.; Pace, M. L.; Utz, R. M.; Haq, S.; Gorman, J.; Grese, M. Freshwater Salinization Syndrome on a Continental Scale. Proc. Natl. Acad. Sci. U. S. A. 2018, 115 (4), E574E583.

(2) Williams, W. D. Salinization: Unplumbed Salt in a Parched Landscape. Water Sci. Technol. 2001, 43, 85-91.

(3) Martín-Queller, E.; Moreno-Mateos, D.; Pedrocchi, C.; Cervantes, J.; Martínez, G. Impacts of Intensive Agricultural Irrigation and Livestock Farming on a Semi-Arid Mediterranean Catchment. Environ. Monit. Assess. 2010, 167 (1-4), 423-435.

(4) Bernhardt, E. S.; Lutz, B. D.; King, R. S.; Fay, J. P.; Carter, C. E.; Helton, A. M.; Campagna, D.; Amos, J. How Many Mountains Can We Mine? Assessing the Regional Degradation of Central Appalachian Rivers by Surface Coal Mining. Environ. Sci. Technol. 2012, 46 (15), 8115-8122.

(5) Cañedo-Argüelles, M.; Brucet, S.; Carrasco, S.; Flor-Arnau, N.; Ordeix, M.; Ponsá, S.; Coring, E. Effects of Potash Mining on River Ecosystems: An Experimental Study. Environ. Pollut. 2017, 224, 759770.

(6) Fitzpatrick, M. L.; Long, D. T.; Pijanowski, B. C. Exploring the Effects of Urban and Agricultural Land Use on Surface Water Chemistry, across a Regional Watershed, Using Multivariate Statistics. Appl. Geochem. 2007, 22, 1825-1840.

(7) Kaushal, S. S.; McDowell, W. H.; Wollheim, W. M. Tracking Evolution of Urban Biogeochemical Cycles: Past, Present, and Future. Biogeochemistry 2014, 121, 1-21.

(8) Kaushal, S. S.; Duan, S.; Doody, T. R.; Haq, S.; Smith, R. M.; Newcomer Johnson, T. A.; Newcomb, K. D.; Gorman, J.; Bowman, N.; Mayer, P. M.; Wood, K. L.; Belt, K. T.; Stack, W. P. HumanAccelerated Weathering Increases Salinization, Major Ions, and Alkalinization in Fresh Water across Land Use. Appl. Geochem. 2017, 83, 121-135.

(9) Corsi, S. R.; Graczyk, D. J.; Geis, S. W.; Booth, N. L.; Richards, K. D. A Fresh Look at Road Salt: Aquatic Toxicity and Water-Quality Impacts on Local, Regional, and National Scales. Environ. Sci. Technol. 2010, 44, 7376-7382.

(10) Kaushal, S. S. Increased Salinization Decreases Safe Drinking Water. Environ. Sci. Technol. 2016, 50 (6), 2765-2766.

(11) Van Meter, R. J.; Swan, C. M.; Leips, J.; Snodgrass, J. W. Road Salt Stress Induces Novel Food Web Structure and Interactions. Wetlands. 2011, 31, 843-851.

(12) Gillis, P. L. Assessing the Toxicity of Sodium Chloride to the Glochidia of Freshwater Mussels: Implications for Salinization of Surface Waters. Environ. Pollut. 2011, 159 (6), 1702-1708.

(13) Kaushal, S. S.; Likens, G. E.; Pace, M. L.; Haq, S.; Wood, K. L.; Galella, J. G.; Morel, C.; Doody, T. R.; Wessel, B.; Kortelainen, P.; Räike, A.; Skinner, V.; Utz, R.; Jaworski, N. Novel "Chemical Cocktails" in Inland Waters Are a Consequence of the Freshwater Salinization Syndrome. Philos. Trans. R. Soc., B 2019, 374 (1764), 20180017.

(14) Schuler, M. S.; Cañedo-Argüelles, M.; Hintz, W. D.; Dyack, B.; Birk, S.; Relyea, R. A. Regulations Are Needed to Protect Freshwater Ecosystems from Salinization. Philos. Trans. R. Soc., B 2019, 374 (1764), 20180019. 
(15) McGlynn, B. L.; McDonnell, J. J. Quantifying the Relative Contributions of Riparian and Hillslope Zones to Catchment Runoff. Water Resour. Res. 2003, DOI: 10.1029/2003WR002091.

(16) Lloyd, C. E. M.; Freer, J. E.; Johnes, P. J.; Collins, A. L. Using Hysteresis Analysis of High-Resolution Water Quality Monitoring Data, Including Uncertainty, to Infer Controls on Nutrient and Sediment Transfer in Catchments. Sci. Total Environ. 2016, 543 (Part A), 388-404.

(17) Basu, N. B.; Thompson, S. E.; Rao, P. S. C. Hydrologic and Biogeochemical Functioning of Intensively Managed Catchments: A Synthesis of Top-down Analyses. Water Resour. Res. 2011, DOI: 10.1029/2011WR010800.

(18) Langlois, J. L.; Johnson, D. W.; Mehuys, G. R. Suspended Sediment Dynamics Associated with Snowmelt Runoff in a Small Mountain Stream of Lake Tahoe (Nevada). Hydrol. Processes 2005, $19,3569-3580$.

(19) McGuire, K. J.; McDonnell, J. J. Hydrological Connectivity of Hillslopes and Streams: Characteristic Time Scales and Nonlinearities. Water Resour. Res. 2010, DOI: 10.1029/2010WR009341.

(20) Vaughan, M. C. H.; Bowden, W. B.; Shanley, J. B.; Vermilyea, A.; Sleeper, R.; Gold, A. J.; Pradhanang, S. M.; Inamdar, S. P.; Levia, D. F.; Andres, A. S.; Birgand, F.; Schroth, A. W. High-frequency Dissolved Organic Carbon and Nitrate Measurements Reveal Differences in Storm Hysteresis and Loading in Relation to Land Cover and Seasonality. Water Resour. Res. 2017, 53, 5345-5363.

(21) Clark, E. V.; Greer, B. M.; Zipper, C. E.; Hester, E. T. Specific Conductance-Stage Relationships in Appalachian Valley Fill Streams. Environ. Earth Sci. 2016, DOI: 10.1007/s12665-016-6026-2.

(22) Wymore, A. S.; Leon, M. C.; Shanley, J. B.; McDowell, W. H. Hysteretic Response of Solutes and Turbidity at the Event Scale Across Forested Tropical Montane Watersheds. Frontiers in Earth Science 2019, DOI: 10.3389/feart.2019.00126.

(23) Williams, G. P. Sediment Concentration versus Water Discharge during Single Hydrologic Events in Rivers. J. Hydrol. 1989, 111, 89-106.

(24) Long, D. T.; Voice, T. C.; Chen, A.; Xing, F.; Li, S.-G. Temporal and Spatial Patterns of $\mathrm{Cl}-$ and $\mathrm{Na}+$ Concentrations and $\mathrm{Cl} / \mathrm{Na}$ Ratios in Salted Urban Watersheds. Elementa 2015, 3, 000049.

(25) Long, D. T.; Voice, T. C.; Xagaroraki, I.; Chen, A.; Wu, H.; Lee, E.; Oun, A.; Xing, F. Patterns of C-q Hysteresis Loops and within an Integrative Pollutograph for Selected Inorganic and Organic Solutes and E. Coli in an Urban Salted Watershed during WinterEarly Spring Periods. Appl. Geochem. 2017, 83, 93-107.

(26) Dewitz, J. National Land Cover Database (NLCD) 2016 Products: U.S. Geological Survey Data Release. 2019.

(27) Benham, B. Department of Biological Systems Engineering, Virginia Tech. Benthic TMDL for Stroubles Creek in Montgomery County, Virginia; Virginia Department of Environmental Quality and Virginia Department of Conservation and Recreation: Richmond, VA, 2003.

(28) Yagow, G.; Benham, B.; Wynn, T.; Younos, T. Upper Stroubles Creek Watershed Draft TMDL Implementation Plan, Montgomery County, Virginia, 2005-13; Virginia Department of Environmental Quality and Virginia Department of Conservation and Recreation: Richmond, VA, 2006.

(29) Muñoz, P.; Drizo, A.; Cully Hession, W. Flow Patterns of Dairy Wastewater Constructed Wetlands in a Cold Climate. Water Res. 2006, 40 (17), 3209-3218.

(30) Wynn, T.; Hession, W. C.; Yagow, G. Stroubles Creek Stream Restoration. Final Project Report; Virginia Department of Conservation and Recreation: Richmond, VA, 2010.

(31) Zhou, D. Restoring Our Urban Streams: A Study Plan for Restoring/Rehabilitating Stroubles Creek in Blacksburg, Virginia. M.S. Thesis of Urban and Regional Planning, Virginia Polytechnic Institute and State University, Blacksburg, VA, 2004.

(32) Parece, T.; DiBetitto, S.; Sprague, T.; Younos, T. The Stroubles Creek Watershed: History of Development and Chronicles of Research. Technical Report SR48-2010; Virginia Water Research Center, 2010.
(33) Hester, E. T.; Guth, C. R.; Scott, D. T.; Jones, C. N. Vertical Surface Water-Groundwater Exchange Processes within a Headwater Floodplain Induced by Experimental Floods. Hydrological Processes. 2016, 30, 3770-3787.

(34) Azinheira, D. L.; Scott, D. T.; Hession, W.; Hester, E. T. Comparison of Effects of Inset Floodplains and Hyporheic Exchange Induced by In-Stream Structures on Solute Retention. Water Resour. Res. 2014, 50, 6168-6190.

(35) Resop, J. P.; Lehmann, L.; Hession, W. C. Drone Laser Scanning for Modeling Riverscape Topography and Vegetation: Comparison with Traditional Aerial Lidar. Drones 2019, 3, 35.

(36) Keys, T. A.; Jones, C. N.; Scott, D. T.; Chuquin, D. A CostEffective Image Processing Approach for Analyzing the Ecohydrology of River Corridors. Limnol. Oceanogr.: Methods 2016, 14, 359-369.

(37) Rogers, M. R. The Assessment of Stream Discharge Models for an Environmental Monitoring Site on the Virginia Tech Campus. MS Thesis, Virginia Tech, 2012.

(38) Liao, H.; Krometis, L.-A. H.; Cully Hession, W.; Benitez, R.; Sawyer, R.; Schaberg, E.; von Wagoner, E.; Badgley, B. D. Storm Loads of Culturable and Molecular Fecal Indicators in an Inland Urban Stream. Sci. Total Environ. 2015, 530-531, 347-356.

(39) O’Donnell, B.; Hotchkiss, E. R. Coupling Concentration- and Process-discharge Relationships Integrates Water Chemistry and Metabolism in Streams. Water Resour. Res. 2019, 55 (12), 1017910190.

(40) Jones, C. N.; Scott, D. T.; Guth, C.; Hester, E. T.; Hession, W. C. Seasonal Variation in Floodplain Biogeochemical Processing in a Restored Headwater Stream. Environ. Sci. Technol. 2015, 49 (22), 13190-13198.

(41) Sanchez R., M.; Hendricks, A. C. Life History and Secondary Production of Cheumatopsyche Spp. in a Small Appalachian Stream with Two Different Land Uses on Its Watershed. Hydrobiologia 1997, 354 (1-3), 127-139.

(42) Govenor, H.; Krometis, L. A. H.; Willis, L.; Angermeier, P. L.; Hession, W. C. Macroinvertebrate Sensitivity Thresholds for Sediment in Virginia Streams. Integr. Environ. Assess. Manage. 2019, 15 (1), 77-92.

(43) Hession, W. C.; Lehmann, L. T.; Wind, L. L.; Lofton, M. E. High-Frequency Time Series of Stage Height, Stream Discharge, and Water Quality (Specific Conductivity, Dissolved Oxygen, PH, Temperature, Turbidity) for Stroubles Creek in Blacksburg, Virginia, USA, 2013-2018. 2020.

(44) R Core Team. R: A Language and Environment for Statistical Computing; R Foundation for Statistical Computing: Vienna, 2019.

(45) Zuecco, G.; Penna, D.; Borga, M.; van Meerveld, H. J. A Versatile Index to Characterize Hysteresis between Hydrological Variables at the Runoff Event Timescale. Hydrological Processes. 2016, 30, 1449-1466.

(46) Muggeo, V. M. R. Interval Estimation for the Breakpoint in Segmented Regression: A Smoothed Score-Based Approach. Australian \& New Zealand Journal of Statistics. 2017, 59, 311-322.

(47) Kelly, V. R.; Findlay, S. E.; Hamilton, S. K.; Lovett, G. M.; Weathers, K. C. Seasonal and Long-Term Dynamics in Stream Water Sodium Chloride Concentrations and the Effectiveness of Road Salt Best Management Practices. Water, Air, Soil Pollut. 2019, DOI: $10.1007 / \mathrm{s} 11270-018-4060-2$.

(48) Bird, D. L.; Groffman, P. M.; Salice, C. J.; Moore, J. SteadyState Land Cover but Non-Steady-State Major Ion Chemistry in Urban Streams. Environ. Sci. Technol. 2018, 52 (22), 13015-13026.

(49) Hasenmueller, E. A.; Criss, R. E.; Winston, W. E.; Shaughnessy, A. R. Stream Hydrology and Geochemistry along a Rural to Urban Land Use Gradient. Appl. Geochem. 2017, 83, 136-149.

(50) Walsh, C. J.; Roy, A. H.; Feminella, J. W.; Cottingham, P. D.; Groffman, P. M.; Morgan, R. P. The Urban Stream Syndrome: Current Knowledge and the Search for a Cure. Journal of the North American Benthological Society. 2005, 24, 706-723.

(51) Oberhelman, A.; Peterson, E. W. Chloride Source Delineation in an Urban-agricultural Watershed: Deicing Agents versus Agricultural Contributions. Hydrol. Processes 2020, 34 (20), 4017-4029. 
(52) Clinton, B. D.; Vose, J. M. Variation in Stream Water Quality in an Urban Headwater Stream in the Southern Appalachians. Water, Air, Soil Pollut. 2006, 169 (1-4), 331-353.

(53) Peter, K. T.; Hou, F.; Tian, Z.; Wu, C.; Goehring, M.; Liu, F.; Kolodziej, E. P. More Than a First Flush: Urban Creek Storm Hydrographs Demonstrate Broad Contaminant Pollutographs. Environ. Sci. Technol. 2020, 54 (10), 6152-6165.

(54) O’Driscoll, M.; Clinton, S.; Jefferson, A.; Manda, A.; McMillan, S. Urbanization Effects on Watershed Hydrology and In-Stream Processes in the Southern United States. Water 2010, 2, 605-648.

(55) McGrane, S. J. Impacts of Urbanisation on Hydrological and Water Quality Dynamics, and Urban Water Management: A Review. Hydrol. Sci. J. 2016, 61, 2295-2311.

(56) Bailey, R. T.; Tavakoli-Kivi, S.; Wei, X. A Salinity Module for SWAT to Simulate Salt Ion Fate and Transport at the Watershed Scale. Hydrol. Earth Syst. Sci. 2019, 23, 3155-3174.

(57) Evans, C.; Davies, T. D. Causes of Concentration/Discharge Hysteresis and Its Potential as a Tool for Analysis of Episode Hydrochemistry. Water Resour. Res. 1998, 34 (1), 129-137.

(58) Snodgrass, J. W.; Moore, J.; Lev, S. M.; Casey, R. E.; Ownby, D. R.; Flora, R. F.; Izzo, G. Influence of Modern Stormwater Management Practices on Transport of Road Salt to Surface Waters. Environ. Sci. Technol. 2017, 51 (8), 4165-4172.

(59) Robinson, H. K.; Hasenmueller, E. A. Transport of Road Salt Contamination in Karst Aquifers and Soils over Multiple Timescales. Sci. Total Environ. 2017, 603-604, 94-108.

(60) Ledford, S. H.; Lautz, L. K.; Stella, J. C. Hydrogeologic Processes Impacting Storage, Fate, and Transport of Chloride from Road Salt in Urban Riparian Aquifers. Environ. Sci. Technol. 2016, 50 (10), 4979-4988.

(61) Robinson, H. K.; Hasenmueller, E. A.; Chambers, L. G. Soil as a Reservoir for Road Salt Retention Leading to Its Gradual Release to Groundwater. Appl. Geochem. 2017, 83, 72-85.

(62) Ludwikowski, J. J.; Peterson, E. W. Transport and Fate of Chloride from Road Salt within a Mixed Urban and Agricultural Watershed in Illinois (USA): Assessing the Influence of Chloride Application Rates. Hydrogeol. J. 2018, 26 (4), 1123-1135.

(63) Olson, J. R. Predicting Combined Effects of Land Use and Climate Change on River and Stream Salinity. Philos. Trans. R. Soc., $B$ 2019, 374 (1764), 20180005. 